\title{
HYPOTHESIS
}

\section{Could inflammatory arthritis be triggered by progenitor cells in the joints?}

\section{Jorgensen, D Noel, G Gross}

Ann Rheum Dis 2002;61:6-9

Fetal morphogenesis genes are expressed in rheumatoid synovial tissue and the presence of undifferentiated mesenchymal cells can also be shown. Possibly, these events are related to remodelling/repair processes, which could lead to the development of new methods of treatment, or they may be harmful and play a part in the immune process.

See end of article for authors' affiliations

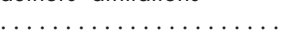

Correspondence to: Dr C Jorgensen, Immuno-rheumatology Department, 34295

Montpellier, cedex 5, France;

jorgens@montp.inserm.fr

Accepted 7 August 2001

...................
M orphogenesis genes are tightly regulated during fetal life, where they are responsible for limb bud initiation, patterning processes of the limb, cartilage development, and joint formation. ${ }^{1}$ These genes are highly conserved across species and include Wnt (wingless), BMP (bone morphogenetic protein), noggin, chordin, FGF (fibroblast growth factor), and hedgehog gene families. Recent studies report that these morphogenesis genes are de novo expressed in rheumatoid synovitis. The presence and potential activity of these genes in adult joints may reflect a new situation: the migration of undifferentiated stromal mesenchymal progenitor cells into the injured joints attracted by the continuing repair process. Another hypothesis would be that the continued persistence of undifferentiated/immature fetal cells in the joints may result in cell activation and immune responses.

\section{LIMB MORPHOGENESIS \\ Limb bud development}

The development of the limb has been studied in great detail. Lateral plate and somatic mesoderm contribute to the formation of the appendicular skeleton. Shortly after the initial outgrowth of the limb bud, somatic cells migrate into the limb to form muscles, nerves, and the vasculature. The skeletal mesenchyme is derived from lateral plate mesoderm and prefigures the future skeletal elements in a cartilaginous primordium in a proximal to distal fashion, so that the humerus forms first, followed by the radius and ulna, and, lastly, the digits.

Cells of the limb bud are embedded in a dynamic three dimensional structure and affected by multiple signalling molecules that ultimately determine their fate. During embryonic life, the elongation of the limb bud in three axes is controlled by FGF-8 (proximal to distal growth), Wnt7 (ventral-dorsal axis), and by Sonic hedgehog (anterior-posterior axis). The initial outgrowth of the limb from the lateral plate mesoderm is induced by the expression of FGF-8 to FGF-10. ${ }^{1}$ In the apical ectodermal ridge, the FGF growth factors are responsible for the proximal to distal elongation of the undifferentiated mesenchyme. FGF-8 induces Sonic hedgehog (Shh) expression that in return is down regulated by FGF-4 through a feedback loop. ${ }^{2}$

\section{Joint formation}

The hedgehog protein family which plays a part in joint formation has the following members: Sonic, Desert, Indian, and Tiggywinkle. Hedgehog family members are secreted proteins that bind a specific receptor (Patch). The signalling cascade include the transcription factor Cubitus interruptus activation of transcription of BMP, Wnt, and Hox genes. ${ }^{3}$ Several wingless proteins (Wnt3, 4, 6, $7 \mathrm{a}$, and En-1, 5a) are expressed in the limb and are involved in joint formation. Wnt proteins bind to a transmembrane receptor frizzled (frz), which then activates the signalling molecule Dishevelled. This signal molecule leads to the activation of a transcription factor complex consisting of $\beta$-catenin/TCF/LEF ( $\mathrm{T}$ cell factor/lymphocyte enhancing factor). Wnt7a shares with Wntl chondrogenesis inhibition of mesenchymal cells. ${ }^{4}$ Retroviral gene transfer of Wntl in the limb buds results in failure of cartilage development. In contrast, Wnt5 induces outgrowth of the proximal skeleton. ${ }^{5}$ Wnt5a/b and Wnt4 genes are expressed in the cartilage primordium of the limb, Wnt5a in the perichondrium, and Wnt4 in the cells of the joint region. Wnt5 expression accelerates chondrocyte maturation, whereas Wnt4 exerts an opposite effect. Wnt 14 has a pivotal role in inducing synovial joint formation in the developing skeleton. In the knee joint of chicken embryo, Wntlu is expressed both by the fibrous connective tissue and the synovial membrane. ${ }^{6}$ Moreover, a local retroviral mediated gene expression of Wntl4 induced ectopic segmentation and new joint formation (fig l). The formation of the joint constitutes a multistep process. The first step is the organisation and condensation of mesenchymal cells, through the expression of Wnt14, followed by GDF5 (fig 1). The BMP antagonists noggin and chordin are responsible for joint space narrowing and counteract the action of BMPs which induce the formation of the joint cavity.

Abbreviations: BMP, bone morphogenetic protein; FGF fibroblast growth factor; IL, interleukin; NFAT, nuclear factor of activated T cells; PG, proteoglycan; RA, rheumatoid arthritis; rBMP, recombinant BMP; TGF $\beta$, transforming growth factor $\beta$; Wnt, wingless 


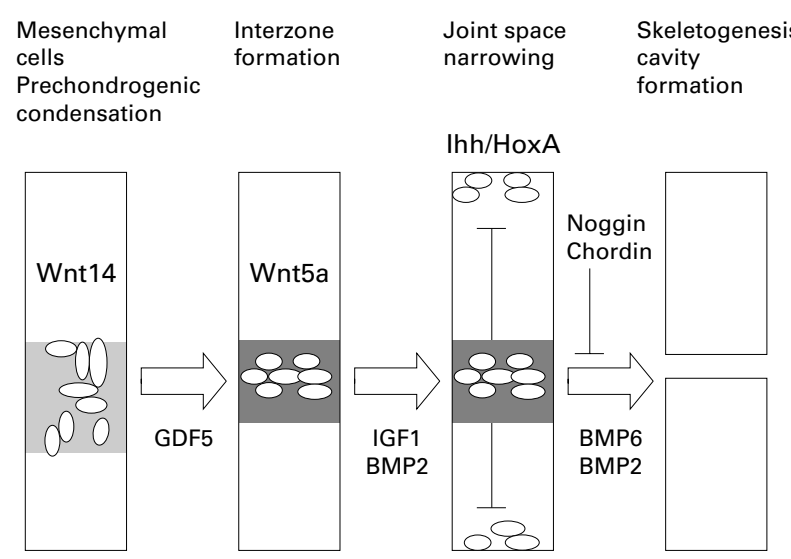

Figure 1 Embryogenesis of the joint.

\section{Skeletogenesis}

Transforming growth factor $\beta$ (TGF $\beta$ ) related molecules, among these, BMPs, regulate many morphogenetic events during embryonic development and are also important signalling molecules for skeletogenesis in vertebrates. The TGF $\beta$ superfamily consists of more than 40 growth factors, which share seven conserved cysteine residues in their C-terminal region. ${ }^{7}$ BMPs are homodimeric proteins of about 20-30 kDa which can induce chondrocytic and osteoblastic differentiation from mesenchymal progenitors and induce osteoblast and chondrocyte related marker gene synthesis, including several types of collagen. In addition, embryonic stem cells may also differentiate into cartilage when stimulated by BMP2 or BMP4. ${ }^{8}$ The BMP family members exert their effect through the association with two different types of serine/threonine kinase receptors: type I and type II receptors. ${ }^{9}$ The type II receptors are involved in initial ligand binding followed by a recruiting of type I receptors into a heteromeric complex, resulting in downstream signalling. A family of nine intracellular signalling proteins, termed Smad proteins (Smadl to Smad9) have been identified in vertebrates, and transduce signals for TGF $\beta .^{10}$ The common mediator Smad (co-Smad; Smad4) associates with activated $\mathrm{R}$-Smads. The Smad complexes translocate into the nucleus and participate in the regulation of target genes. This occurs predominantly by the binding of other transcription factors and transcription regulators. The third class of Smads are inhibitory molecules (I-Smads, Smad6 and Smad7) which interfere with the activation of R-Smads.

\section{"Are morphogenesis genes related to the continuing remodelling/repair process in chronic autoimmune synovitis?"}

The Smad cascade leads to expression of transcription factors Scleraxis, HMG box protein Sox9, and paired box genes Paxl and Pax9, which play a pivotal role during chondrogenesis. Teratomas generated from Sox9-/- mutant embryonic stem cells do not produce cartilage tissue, indicating a requirement for cartilage formation. ${ }^{11}$ Furthermore, in chimeric mice Sox9-/- or Scleraxis-/- cells do not contribute to the formation of chondrogenic or skeletal structures. ${ }^{11}{ }^{12}$ During embryogenesis, the paired-box transcription factors Paxl and Pax9 are expressed in axial and limb skeletal elements, and targeted deletions in mice display phenotypes in these elements, indicating a role for these factors in patterning and cartilage formation. ${ }^{13}{ }^{14}$ Recently, a $\mathrm{T}$ box domain-containing transcription factor was shown to induce chondrocyte differentiation and cartilage formation (Czichos S et al, unpublished data).
Chondrogenesis is also negatively regulated during embryogenesis by the nuclear factor of activated T cells (NFATp). NFATp-/- mice develop ectopic formations of cartilage and show extensive destruction of peripheral joints after 6 months of age. ${ }^{15}$ Zinc finger transcription factors such as $\alpha$ A-crystallin binding protein 1 (CRYBPl) seem to interfere with collagen II synthesis ${ }^{16}$ and a targeted $\delta E F 1$ deletion in mice leads to severe defects in skeletal patterning and joint formation. ${ }^{17}$ Several additional factors play a part in chondrogenesis negative regulation during embryogenesis for endochondral bone formation. Among these, noggin is a natural BMP antagonist, which down regulates mesenchymal cell recruitment in cartilage and slows cartilage progression. ${ }^{18}$ Noggin-/- mice show a normal BMP distribution. These animals exhibit several skeletal phenotypes such as hyperplasia of cartilage primordia and fusion of several skeletal elements. Interestingly, these mutant animals fail to develop joints or lumbar tail vertebrae. Parathyroid hormone related protein and Indian hedgehog establish a negative feedback loop which blocks transition of proliferative chondrocytes into hypertrophy. Insulin-like growth factors and FGFs seem to stimulate chondrocyte proliferation in an age dependent manner. ${ }^{19} 20$

\section{IMMATURE PROGENITOR CELLS IN ADULT SYNOVIAL TISSUE}

Numerous fetal genes are expressed in adult injured tissues. In autoimmune processes, tissue remodelling occurs simultaneously with inflammation. This remodelling process is distinct from wound healing: instead of fibrosis and repair, mesenchymal cells migrate to the injured organ and rebuild the tissue through a morphogenesis process (Czichos $\mathrm{S}$ et al, unpublished data).

In arthritic joints, such undifferentiated mesenchymal cells have been described. ${ }^{21}$ These cells have been designated as pannocytes and can be distinguished from synoviocytes or chondrocytes through their rhomboid morphology and the high proliferative response to TGF $\beta$. Within the synovium, mesenchymal cells express BMP receptor, vimentin, and CD44, but not the haemopoietic marker CD34. The cells represent $25 \%$ of the synovial lining layer in rheumatoid arthritis (RA). ${ }^{22}$ Another study reported that within the RA pannus, synovial cells possess a chondrogenic potential. These cells differentiated into chondrocytes in the presence of TGF $\beta$, or to osteoblasts when stimulated by dexamethasone and ascorbate. ${ }^{22}$ In rabbit, synovial progenitor cells are described in the normal synovium, with chondrogenic properties. ${ }^{23}$ These data demonstrate the pluripotency of these synovial mesenchymal stem cells.

\section{MORPHOGENESIS GENE EXPRESSION IN RA SYNOVITIS}

Adult synovial cells can produce morphogenesis genes such as BMP2 in the case of inflammation. In vitro, BMP2 has been shown to be produced by rheumatoid synoviocytes after interleukin (IL) 1 stimulation. ${ }^{24}$ BMPs are involved in bone healing as well as in cartilage metabolism in adults. In the joint, BMP2 induces extracellular matrix synthesis from chondrocytes and cartilage growth. Injection of recombinant BMP2 (rBMP2) into the joint induced proteoglycan (PG) synthesis in a dose dependent manner, up to three times the initial value. ${ }^{25}$ BMP2 was more efficient than TGF $\beta 1$ in stimulation of PG synthesis, but its biological effect was more restricted. However, in the case of induced arthritis in the rabbit, rBMP2 injection in joints was unable to restore PG synthesis. This study showed that the stimulatory activity of PG synthesis by rBMP2 was unable to interfere with ILl $\alpha$ induced PG depletion. ${ }^{26}$ In contrast with BMP2, BMP7/OP1 was effective in restoring PG synthesis by chondrocytes in culture despite the presence of $\operatorname{ILl} \beta .^{27}$ 
Other fetal morphogenesis genes have been described in rheumatoid synovial tissue. Among these, wingless genes (Wntl, 5a, 10b, 11, 13) could be detected in three of five RA samples as well as their receptor frizzled isoforms (frz2, 5, 7). ${ }^{28}$ Thus Wnt5a and frz5 expression seem to be specific for RA compared with osteoarthritis or with normal tissue specimens. ${ }^{28}$ The levels of Wnt5a expression were equivalent to embryonic cells. Surprisingly, transfection of normal synovial cells with Wnt5a increased expression of proinflammatory cytokines to levels seen in RA synoviocytes. Wnt5a has been shown to interact with the cell surface receptors frz5 and frz2, present on synoviocytes. Treatment of synovial cells with antifrz5 reduced IL6 and IL15 expression. ${ }^{29}$ The simultaneous expression of ligand/receptor on RA synoviocytes suggests that cytokine induction is mediated by an autocrine loop involving Wnt binding to frz. Simultaneously, the morphogenesis gene homeobox Hoxd9, a transcription regulator, is expressed by RA synovial cells. ${ }^{30}$ This gene expression is involved in synovial synthesis of FGF $\beta$ and tumour necrosis factor $\alpha$.

\section{"Aberrant expression of fetal morphogenesis genes in adults may be harmful"}

Remarkably, a number of these fetal genes are not limited to the synovial tissue and are involved in immune cell activation. For example, NFAT induces cardiac valve formation, T cell activation, and chondrocyte growth and differentiation in adult animals. ${ }^{15}$ The Wnt lob gene, expressed in fetal tissue, is induced after helper $\mathrm{T}$ cell activation in adults. ${ }^{31}$ Another example is the down regulation of the receptor for frzl and frz2 expression on aortic smooth muscle cells in response to balloon injury. ${ }^{32}$ This modulation follows the proliferative state of the cells, and shows that Wnt signalling components are involved in joint, lung, or vascular diseases.

\section{WHY ARE FETAL GENES EXPRESSED IN INFLAMED ADULT TISSUES?}

The first hypothesis to explain expression of morphogenesis genes and mesenchymal stem cells in autoimmune lesions is that these events are related to remodelling/repair processes. In contrast with wound healing, a new expression of fetal genes seems appropriate to obtain restitution ad integrum of the organ.

The second hypothesis is that the persistence of immature progenitors in the RA synovial tissue is involved in the immune process. In RA, synoviocytes have a transformed phenotype characterised by anchorage independent proliferation and invasiveness. These cells expand clonally and express genes involved in entry and progression in the cell cycle, including c-myc, c-jun, jun-b, c-fos, and erg- 1 , and simultaneously underexpress cyclin inhibitors like Cip/Kip and INK4. ${ }^{33}$ Wnt is a proto-oncogene that promotes cell proliferation and transformation of cell phenotype, leading to tumour formation when associated with a loss of $\mathrm{p} 53$ function. ${ }^{34}$ Overexpression of Wntlob in transgenic mice results in a profound alteration of the mammary gland, an expanded glandular development, and an increased adenocarcinoma susceptibility. ${ }^{35}$ Wnt5a secreted by synoviocytes binds to frz receptor and leads to activation of the protein kinase $C$ cascade and NFKB activation. ${ }^{36}$ Overexpression of Wnt5a in synovial tissue may induce cell transformation and proinflammatory cytokine expression.

Overexpression of fetal genes associated with the presence of undifferentiated mesenchymal cells in autoimmune diseases opens new perspectives for investigation. The effect of this aberrant expression of fetal genes in adult life may be harmful if related to chronic immune activation. On the other hand, knowledge of the possible reactivation of the morphogenesis process in adult tissue may lead to new concepts for future therapeutic intervention.

\section{Authors' affiliations}

C Jorgensen, D Noel, Immuno-rheumatology Department, INSERM U475, 34295 Montpellier, France

G Gross, Osteogenesis Group, GBF (German Biotechnological Research Centre), Mascheroder Weg 1, 38124 Braunschweig, Germany

\section{REFERENCES}

1 Sandell LJ, Adler P. Developmental patterns of cartilage. Front Biosci 1999:4:731-42.

2 Laufer E, Nelson C, Johnson R, Morgan B, Tabon C. Shh and FGF4 act through a signalling cascade and feedback loop to integrate growth and patterning of the development of limb bud. Cell 1994;79:993-1003.

3 Iwasaki $M$, Le AX, Helms JA. Expression of indian hedghog, Bmp6 and Gli during skeletal morphogenesis. Mech Dev 1997;69:197-202.

4 Rudnicki J, Brown A. Inhibition of chondrogenesis by Wnt gene expression in vivo and in vitro. Dev Biol 1997; 185:104-18.

5 Yamaguchi TP, Bradley A, McMahon AP, Jones S. A Wnt5a pathway underlies out growth of multiple structures in the vertebrate embryo. Development 1999; 126:1211-23

6 Hartmann C, Tabin CJ. Wnt 14 plays a pivotal role in inducing synovial joint formation in the developing appendicular skeleton. Cell $2001 ; 104: 341-51$

7 Wozney JM, Rosen V. Bone morphogenetic protein and bone morphogenetic protein gene family in bone formation and repair. Clin Orthop 1998;346:26-37

8 Kramer J, Hegert C, Guan K, Wobus AM, Muller P, Rohwedel J. Embryonic stem cell derived chondrogenic differentiation in vitro: activation by BMP2 and BMP4. Mech Dev 2000;92:193-205.

9 Massagué J, Attisano L, Wrana JL. The TGF- $\beta$ family and its composite receptors. Trends Cell Biol 1994;4:172-8.

10 Heldin CH, Miyazono K, Ten Dijke P. TGF- $\beta$ signalling from cell membrane to nucleus through SMAD proteins. Nature 1997:390:465-71.

11 Bi W, Deng JM, Zhang Z, Behringer RR, de Crombrugghe B. Sox9 is required for cartilage formation. Nat Genet 1999;22:85-9.

12 Brown D, Wagner D, Li X, Richardson JA, Olson EN. Dual role of the basic helix-loop-helix transcription factor scleraxis in mesoderm formation and chondrogenesis during mouse embryogenesis. Development 1999; 126:4317-29.

13 Timmons PM, Wallin J, Rigby PWJ, Balling R. Expression and function of Pax 1 during development of the pectoral girdle. Development 1994; 120:2773-85

14 Peters H, Neubüser A, Kratochwil K, Balling R. Pax9-deficient mice lack pharyngeal pouch derivatives and teeth and exhibit craniofacial and limb abnormalities. Genes Dev 1998; 12:2735-47.

15 Ranger AM, Gerstenfeld LC, Wang J, Kon T, Bae H, Gravallese EM, et al. The nuclear factor of activated T cells (NFAT) transcription factor NFATp (NFATc2) is a repressor of chondrogenesis. J Exp Med 2000;191:9-21.

16 Tanaka K, Matsumoto Y, Nakatani F, Iwamoto Y, Yamada Y. A zinc finger transcription factor, alphaA-crystallin binding protein 1 , is a negative regulator of the chondrocyte-specific enhancer of the alpha 1 (II) collagen gene. Mol Cell Biol 2000;20:4428-35

17 Takagi T, Moribe H, Kondoh H, Higashi Y. DeltaEF 1, a zinc finger and homeodomain transcription factor, is required for skeleton patterning in multiple lineages. Development 1998;125:21-31.

18 Brunet LJ, McMahon JA, McMahon AP, Harland RM. Noggin, cartilage morphogenesis and joint formation in the mammalian skeleton. Science 1998;280: 1455-7

19 Vortkamp A, Lee K, Lanske B, Segre G, Kronenberg HM, Tabin CJ. Regulation of rate of cartilage differentiation by iondian hedghog and PTH related protein. Science 1996:273:613-22.

20 Baker J, Liu JP, Robertson EJ, Efstratiadis A. Role of insulin like growth factors in emryonic and postnatal growth. Cell 1993;75:73-82.

21 Zvaifler NJ, Tsai V, Alsalameh S, Vonkempis J, Firestein GS, Lotz M. Pannocytes: distinctive cells found in rheumatoid arthritis articular cartilage erosions. Am J Pathol 1997;150:1125-38.

22 Marinova-Mutafchieva L, Taylor P, Funa K, Maini RN, Zvaifler NJ. Mesenchymal cells expressing bone morphogenetic protein receptors are present in the rheumatoid arthritis joint. Arthritis Rheum 2000:43:2046-55

23 Nishimura K, Solchaga LA, Caplan Al, Yoo JU, Goldberg VM Johnstone B. Chondroprogenitor cells of synovial tissue. Arthritis Rheum 1999;42:2631-7

24 Fowler MJ, Neff MS, Borghaei RC, Pease EA, Mochan E, Thornton RD. Induction of BMP-2 by IL 1 in human fibroblasts. Biochem Biophys Res Commun 1998;248:450-3

25 Sellers R, Peluso D, Morris EA. The effect of recombinant human BMP2 on the healing of full thickness of articular cartilage. J Bone Joint Surg 1997;79: 1452-63.

26 Glansbeek HL, van Beuningen HM, Vitters EL, Morris EA, van der Kraan $P M$, van den Berg WB. Bone morphogenetic protein 2 stimulates articular cartilage proteoglycan synthesis in vivo but does not counteract interleukin- $1 \alpha$ effects on proteoglycan synthesis and content. Arthritis Rheum 1997:40:1020-8.

27 Lietman SA, Yanagishita M, Sampath TK, Reddi H. Stimulation of proteoglycan synthesis in explants of porcine articular cartilage by 
recombinant osteogenic protein-1 (bone morphogenetic protein-7). J Bone and Joint Surg Am 1997;79:1 132-7.

28 Sen M, Lauterbach K, El-Gabalawy H, Firestein G, Corr M, Carson DA. Expression and function of wingless and frizzled homologs in rheumatoid arthritis. Proc Natl Acad Sci USA 2000;10:1073-86.

29 Sen M, Chamorro M, Carson DA. Inhibition of synovial fibroblast activation in RA by blockade of $\mathrm{Wnt5a}$ and frizzled 5 [abstract]. Arthritis Rheum 2000;43(suppl):S159

30 Nguyen Ngoc Chau, Nakazawa M, Nakamura H, Kobata T, Nishioka K, Kanawaka K. Synovial fibroblasts with HoxD9 protein escape from apoptosis in vivo [abstract]. Arthritis Rheum 2000;43(suppl):S161

31 Hardiman G, Albright S, Tsunoda J, McClanahan T, Lee F. The mouse Wnt $10 \mathrm{~b}$ gene isolated from helper $\mathrm{T}$ cells is widely expressed and a possible oncogene in BR6 mouse mammary tumorigenesis. Gene 1996; 172:199-205.
32 Mao C, Malek OT, Pueyo ME, Steg PG, Soubrier F. Differential expression of rat frizzled related $\mathrm{frzb}_{1}$ and $\mathrm{fz}$ receptor 1 and $\mathrm{fz} 2$ genes in the rat aorta after ballon injury. Arterioscler Thromb Vasc Biol 2000;20:43-51.

33 Vollin MV, Koch AE. Cell cycle implications in the pathogenesis of RA. Front Biosci 2000; 1:594-601.

34 Wang J, Shou J, Chen X. Dickopf-1 an inhibitor of the Wnt signaling pathway, is induced by p53. Oncogene 2000;19:1843-8.

35 Lane TF, Leder P. Wnt 10b directs hypermorphic development and transformation in mammary glands of male and female mice. Oncogene 1997; 15:2133-44.

36 Sheldahl LC, Park M, Malbon CC, Moon RT. PKC is differentially stimulated by $\mathrm{Wnt}$ and frizzled homologs in a $\mathrm{G}$ protein dependent manner. Curr Biol 1999;1:695-8.

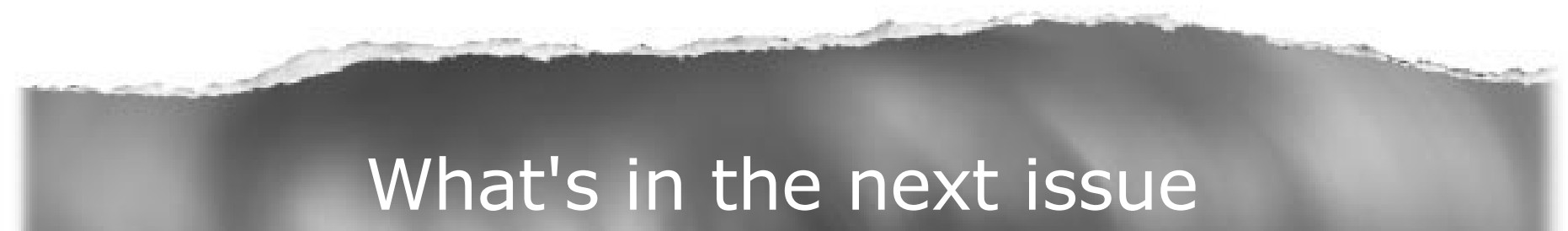

\section{Future content}

See which articles have just been accepted for publication and preview the table of contents for the next issue a month before it is published

\section{wWW.annrheumdis.com}

